\title{
Optimal incentive contracts under inequity aversion ${ }^{t}$
}

\author{
Florian Englmaier ${ }^{\mathrm{a}, *}$, Achim Wambach ${ }^{\mathrm{b}}$ \\ a University of Munich, Ludwigstr. 28 III VG, D-80539 Munich, Germany \\ b University of Cologne, Albertus-Magnus-Platz, D-50923 Cologne, Germany
}

A R T I C L E I N F O

\begin{tabular}{l}
\hline JEL classification: \\
D23 \\
D63 \\
J31 \\
J33 \\
M12 \\
Z13 \\
Keywords: \\
Contract theory \\
Linear contracts \\
Incentives \\
Sufficient statistics result \\
Inequity aversion \\
Incomplete contracts
\end{tabular}

\begin{abstract}
A B S T R A C T
We analyze the classic moral hazard problem with the additional assumption that agents are inequity averse. The presence of inequity aversion alters the structure of optimal contracts. When the concern for equity becomes more important, there is convergence towards linear sharing rules. The sufficient statistics result is violated. Depending on the environment, contracts may be either overdetermined, i.e. include non-informative performance measures, or incomplete, i.e. neglect informative performance measures. Finally, our model delivers a simple rationale for team based incentives, implying wage compression.
\end{abstract}

\section{Introduction}

"A given level of pay may be viewed as good or bad, acceptable or unacceptable, depending on the compensation of others in the reference group, and as such may result in different behavior. [...] This is a constraint on the use of any sort of incentive pay."

Milgrom and Roberts (1992, p. 419)

Although Milgrom and Roberts (1992) clearly state that social preferences matter in the design of incentive schemes this issue has received little attention - though the question how to provide appropriate incentives was analyzed in much detail since Holmström's (1979) seminal paper on Moral Hazard. ${ }^{1}$ Recently, motivated by real-world anomalies and many experimental results, ${ }^{2}$ there has been a lot of interest in social preferences and theoretical frameworks have been developed

\footnotetext{
We thank Tobias Böhm, Florian Ederer, Tore Ellingsen, Ernst Fehr, Alexander Rasch, Ray Rees, Arno Schmöller, Hans Zenger and seminar participants at University College London, the London School of Economics, the Stockholm School of Economics, the Harvard/MIT Organizational Economics Seminar, and the Zeuthen Workshop in Behavioral Economics for their comments. The paper benefited a lot by the comments from the editor Matthew Jackson and an anonymous referee.

* Corresponding author. Fax: +4989218099 3916.

E-mail addresses: englmaier@lmu.de (F. Englmaier), wambach@wiso.uni-koeln.de (A. Wambach).

1 Kandel and Lazear's (1992) work on peer pressure is one of the few exceptions.

2 See e.g. Fehr and Schmidt (2003) for a comprehensive survey of these experimental studies.
} 
to model other-regarding preferences. However, so far little work has been done to see how classical contract-theoretic predictions change when social preferences enter the picture. This paper takes steps in this direction.

We introduce social preferences, captured by inequity aversion in the spirit of Fehr and Schmidt (1999) and Bolton and Ockenfels (2000), ${ }^{3}$ into a Holmström (1979) setting where a principal hires an agent who, by his choice of effort, determines the probability distribution of profits. Although one may look at a variety of contract-theoretic models and consider a variety of ways how social preferences matter, ${ }^{4}$ we choose these widely cited classics as natural starting points of an analysis in this field. In this new situation, we find that the optimal contract has to trade off three factors: insurance, incentives, and fairness. The agent's concern for a fair distribution of profits leads to a tendency towards linear sharing rules. Furthermore this concern delivers a new incentive instrument, as the agent can be rewarded for good performance not only by paying more, but also by paying more equitably. Moreover we find that Holmström's sufficient statistics result ${ }^{5}$ is violated as optimal contracts may be either overdetermined or incomplete. Finally, turning to the multiple-agents case, the fairness motive gives a rationale for the widespread use of team incentives even if the performed tasks are independent. This latter effect also implies wage compression, as for example described by Frank (1984), compared to the situation without inequity aversion.

We find that analyzing the moral hazard problem with an agent that suffers from being worse off or better off than the principal delivers predictions that can explain several empirical regularities that cannot be easily explained by standard models. The intuition why inequity aversion leads to a tendency towards linear sharing rules in our model is straightforward. An inequity averse agent cares for everybody getting a "fair share" of surplus. Every additional unit of surplus has to be distributed according to these fair shares, implying a linear sharing rule. Similarly we find that optimal contracts may violate Holmström's (1979) sufficient statistics result. Contracts may be overdetermined as inequity aversion implies an intrinsic interest in the distribution of firms' profits. Even if profit consists not only of parts influenced by agents' effort choices, agents might still want to participate in variations of overall profit. On the other hand this intrinsic interest in a firm's profit might render it infeasible to contract on better performance measures than profit as this might lead to too inequitable distributions. Thus contracts may be incomplete in equilibrium. Hence, as inequity aversion generates an intrinsic interest in the distribution of profit, we should expect non-informative measures of profit to be included and informative but not profit related measures to be excluded from contracts. Finally, our analysis offers an explanation for the prominence of team incentives. If workers care about each others payoffs it may be optimal to condition workers' pay on their co-workers' performance. This type of team incentives can be interpreted as an insurance not only against income shocks but also against the disutility from being worse or better off than the co-workers. An implication of this insurance is that wages are more compressed than they would be in absence of workers' inequity aversion.

A few recent papers have dealt with the matter of incorporating social preferences into contract theory. ${ }^{6}$ Itoh (2004) and Dur and Glazer (2008) are closest to our setting. However, these two papers restrict attention to discrete outcomes and the agent's effort choice to a binary decision while we allow both to be continuous.

A different approach to incorporate social preferences into a contracting problem is pursued by Hart and Moore (2008). They analyze an incomplete contracting environment and argue that contracts provide reference points for the contracting parties' feelings of entitlement. Hart and Moore (2008) focus on the tradeoff between flexibility and rigidity. A flexible contract maximizes the ex-post probability of trade but also causes the most extreme feelings of entitlement. Conversely, an ex ante contract that pins down future outcomes very precisely, and therefore leaves little room for disagreement and agreement has the drawback that it does not allow the parties to adjust to different states of the world. Fehr et al. (2008) examine experimentally the behavioral forces stipulated in Hart and Moore (2008) and find evidence for the model's predictions. Englmaier and Leider (2008) incorporate reciprocal preferences, as developed by Rabin (1993), Dufwenberg and Kirchsteiger (2004), or Falk and Fischbacher (2006), into a moral hazard model and derive properties of the optimal contract and implications for organizational structure. Charness and Dufwenberg (2006) present a theory of guilt aversion in a principal-agent game with hidden action and test their prediction, namely that agents try to perform as to conform to others' expectations, experimentally. They vary the communication structure and document that players tend to keep their non-binding promises, which squares well with the notion of guilt-aversion.

The remainder of this paper is structured as follows. In Section 2 we set out the model and derive and discuss the structure of optimal contracts for the situations where effort is contractible and non-contractible, respectively. We also discuss our assumptions and their implications in detail. Section 3 contains extensions where we first allow for additional signals and address the question of contractual completeness and then study the multi-agent case. Section 4 compares our main findings with several stylized empirical facts. Section 5 concludes. All proofs are collected in Appendix A.

\footnotetext{
3 Both in Fehr and Schmidt (1999) and Bolton and Ockenfels (2000) the agents' utility increases in own profit but decreases if they are better or worse off than others. While in Fehr and Schmidt (1999) agents compare own payoffs to everybody else's payoff, in Bolton and Ockenfels (2000) they compare themselves only to the average in the reference group. For almost all of our results the two models coincide in their predictions as there are only two players.

4 Among the most prominent examples of models of other-regarding preferences are Rabin (1993), Dufwenberg and Kirchsteiger (2004), Falk and Fischbacher (2006), Cox et al. (2007), and Charness and Rabin (2002).

5 The sufficient statistics result states that optimal contracts should condition on all informative signals with respect to effort choice and not on uninformative signals.

6 For a comprehensive treatment of this literature see Englmaier (2005).
} 


\section{The model}

We employ the framework from Holmström (1979) to model the interaction between a risk neutral, profit maximizing principal and a utility maximizing agent who is inequity averse towards his principal. In Section 3.3 we extend the framework to deal with the case of multiple agents, exhibiting inequity aversion towards each other and towards the principal.

\subsection{Set up}

The principal hires the agent to work for him. The profit $x$ realized at the end of the period is continuously distributed in an interval $[\underline{x}, \bar{x}]$ with density $f(x \mid e)$ which is determined by the effort $e$ exerted by the agent. As the principal is neither risk averse nor inequity averse he wants to maximize his expected net profit

$$
E U_{P}=\int_{\underline{x}}^{\bar{x}} f(x \mid e)[x-w(x)] d x
$$

where $w(x)$ is the wage paid to the agent.

We model the agent in the spirit of Fehr and Schmidt (1999) and assume that he cares about his relative payoff. The agent's utility function is additively separable and has three parts: First, he derives utility from wealth, $u(w(x))$, which is strictly increasing in the wage payment. Second, he suffers a cost $c(e)$ from exerting effort with $c^{\prime}(e)>0$. Finally the function $G(\cdot)$ captures his concern for equitable allocations. To decide whether an allocation is fair or unfair the agent compares his payoff $w(x)$ and the principal's net payoff $[x-w(x)] .^{7}$ Therefore the agent's utility is given by

$$
\begin{aligned}
E U_{A}= & u(w(x))-c(e)-\alpha G([x-w(x)]-w(x)) \\
\text { with } \quad & G^{\prime}(\cdot)>0 \quad \text { if }[x-w(x)]>w(x), \quad G^{\prime}(\cdot)<0 \quad \text { if }[x-w(x)]<w(x) \\
& G^{\prime \prime}(\cdot)>0 \\
& G(0)=0, \quad G^{\prime}(0)=0 \\
& \alpha>0
\end{aligned}
$$

where $\alpha$ is the weight the agent puts on achieving equitable outcomes. ${ }^{8}$ One could think of this weight embedded in $G(\cdot)$, but to ease comparative statics we write it explicitly.

Fig. 1 shows one possible graph of $-G(\cdot)$. A quadratic function would be an example for a function fulfilling our assumptions. However, the function has by no means to be symmetric around 0 , i.e. the equitable allocation. Thus we allow for the agent suffering much more from disadvantageous inequity than from advantageous inequity. Assuming convexity of $G(\cdot)$ implies an aversion towards lotteries over different levels of inequity.

We assume that the agent can ensure himself a utility level $\bar{U}$ in the outside market implying that the principal has to obey the agent's participation constraint $E U_{A}>\bar{U}$. We also assume that the Monotone Likelihood Ratio Property, Milgrom (1981), applies, i.e.

$$
\frac{\partial\left(\frac{f_{e}(x \mid e)}{f(x \mid e)}\right)}{\partial x}>0 .
$$

This implies that the higher the realization of profit the more likely it is that high effort was exerted. Furthermore we follow Innes (1990) and assume that the agent can secretly boost or destroy profits. This ensures that the slope of the optimal contact is bounded between $0 \leqslant w^{\prime}(x) \leqslant 1$.

\subsection{Contractible effort}

We start our analysis with the case where the principal can contract on effort, i.e. there is no moral hazard problem present. In this situation the principal wants to maximize his expected profit net of wage payments and has to obey only the agent's participation constraint (PC). Thus the problem becomes

\footnotetext{
7 In the Fehr-Schmidt model, the agent is risk neutral with respect to wealth, $u(w(x))=w(x)$, and the inequity aversion term is formulated slightly different. We comment upon these differences in Section 2.4. Note that our results qualitatively also hold for a model where the agent compares his net payoff (wage-effort costs) to the principal's net payoff (income-wage). See Section 2.4 for a discussion. A formal exposition of this case can be found in the working paper version of this paper which is available from the authors.

8 Note that, by setting $\alpha=0$, we are back to the original Holmström (1979) model.
} 


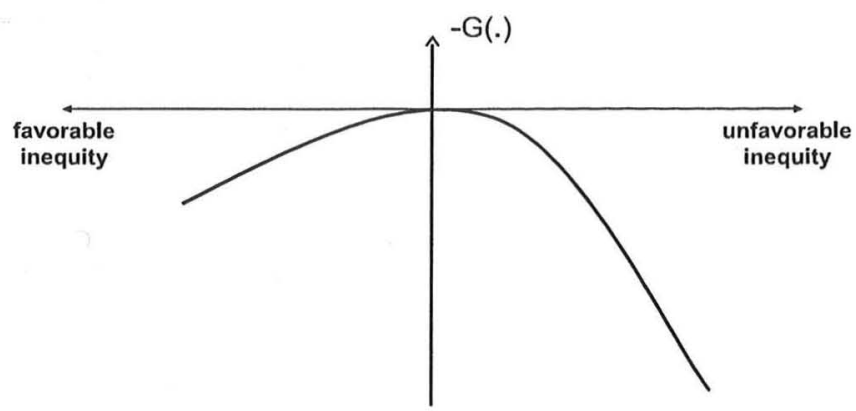

Fig. 1. Example for $-G($.).

$$
\begin{aligned}
& \max _{e, w(x)} E U_{P}=\int_{\underline{x}}^{\bar{x}} f(x \mid e)[x-w(x)] d x \\
& \text { s.t. } \quad(P C) \quad E U_{A}=\int_{\underline{x}}^{\bar{x}} f(x \mid e)[u(w(x))-\alpha G(x-2 w(x))] d x-c(e) \geqslant \bar{U} .
\end{aligned}
$$

To isolate effects we first assume the agent to be risk neutral with respect to variations in income, i.e. $u(w(x))=w(x)$. In standard contracting models the contract structure in this setting is entirely undetermined. The principal is just interested in extracting all the rent from the relationship and as there is no risk aversion as a source of deadweight loss he can do so with any contract. However, introducing inequity aversion changes the picture.

Proposition 1. If effort is contractible and the agent is risk neutral with respect to wealth the unique optimal contract is linear with slope $\frac{1}{2}$.

Proof. This and all following proofs are given in Appendix A.

The intuition for this result is that inequity aversion is the only source of welfare loss in the problem. Similar to risk aversion here the agent dislikes variations in inequity. Thus the deadweight loss can be minimized by offering a constant level of inequity over all realizations of $x$, i.e. a linear contract with slope $\frac{1}{2}$. Generically there will be a deadweight loss in equilibrium as the principal extracts the rent with a lump sum payment, thus inflicting some inequity on the agent. However, the principal's ability to use this lump sum payment is restricted by the agent's concern for inequity.

Corollary 1. With contractible effort and a risk neutral agent the principal's profit decreases in the agent's concern for inequity, $\alpha$.

To see this, first consider the case where leaving the agent half the surplus suffices to make him participate and even makes him better off than with his outside option. Now the principal extracts this rent via the lump sum payment. This reduces the agent's utility by making him poorer and by inflicting inequity on him. For a higher $\alpha$, i.e. more concern for inequity, this latter effect is more pronounced and the principal can extract only a lower lump sum payment. In the case where leaving the agent half the surplus does not suffice to make him participate and violates the participation constraint, the principal induces participation of the agent by paying him a lump sum transfer. The agents' utility increases as he is now richer but this effect is dampened as the utility is decreased due to the induced inequity. This latter effect is more pronounced for a higher $\alpha$. Thus the principal has to pay a higher transfer to make the agent participate. ${ }^{9}$

Proposition 1 gives us the prerequisites to fully describe all the forces at work in our model. Fig. 2 shows these three forces. As in standard models the agent's insurance motive calls for a flat wage as this takes away all the income risk from him. The principal's wish to provide incentives calls for a wage scheme that makes the agent residual claimant of profits, i.e. has a slope of 1 . Finally, inequity aversion calls for an equal sharing rule as this insures the agent against variations in the level of inequity.

With this at hand we can enrich our model by introducing risk aversion for the agent. In standard models of contract theory with full information the solution is simply offering the agent a flat wage. As there is no need to provide incentives, the principal just has to ensure that the agent is fully insured. However, including inequity aversion alters the situation.

9 For Corollary 1 to hold we have to impose $\alpha G^{\prime}(\cdot)>-\frac{1}{2}$. This assumption rules out that the agent is willing to transfer money to the principal when he is better off in order to reduce inequity. Fehr and Schmidt (1999) impose a similar assumption, namely that $\beta$, i.e. the compassion term, is sufficiently small. Also note that, in some cases, due to a high degree of inequity aversion it may not be possible to make the agent willing to participate at all. 


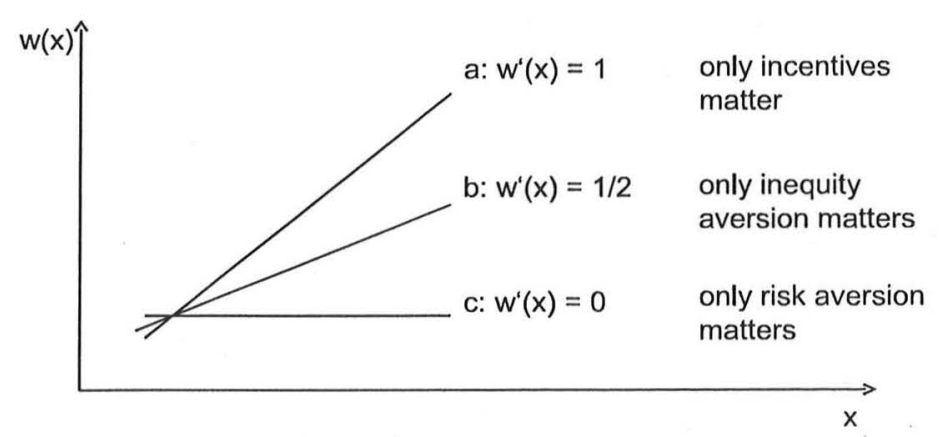

Fig. 2. Driving forces for the wage structure.

Looking at Fig. 2 we see that as there is not yet a need to provide incentives, the optimal contract's structure will be determined in the interplay of risk aversion (calling for a flat wage) and inequity aversion (calling for an equal sharing rule).

Proposition 2. If effort is contractible and the agent is risk averse with respect to wealth the optimal contract is strictly increasing with a slope between 0 and $1 / 2$.

The results of this section imply that in the presence of inequity aversion we should always observe some profit sharing, even if it is not necessary for incentive reasons or when profits are not a good performance measure. Section 4 contains several observations backing this conjecture.

\subsection{Non-contractible effort}

Now we turn to the analysis of the classical moral hazard problem as we drop the assumption that effort can be contracted upon. Thus the optimal contract has to be self-enforcing, i.e. the agent has to find it in his own best interest to act as desired by the principal. This incentive constraint (IC) the principal has to obey in addition to the above introduced participation constraint has the form

$$
\text { (IC) } e \in \arg \max _{\tilde{e}} E U_{A}=\int_{\underline{x}}^{\bar{x}} f(x \mid \tilde{e})[u(w(x))-\alpha G(x-2 w(x))] d x-c(\tilde{e})
$$

and captures the fact that the agent will maximize his utility by choosing effort optimally given the offered compensation scheme.

In order to solve the problem we rely, as it is standard in the literature, on the first order approach ${ }^{10}$ and replace the above maximization problem by its first order condition

$$
\left(\mathrm{IC}^{\prime}\right) \quad 0=\int_{\underline{x}}^{\bar{x}} f_{e}(x \mid e)[u(w(x))-\alpha G(x-2 w(x))] d x-c^{\prime}(e) .
$$

\subsubsection{Risk neutral agents}

First we look again at the case of a risk neutral agent, $u(w(x))=w(x)$. The standard contracting model (with a noninequity averse agent) delivers a simple way to efficiently implement the first best effort level: The principal chooses a franchise solution ("sells the firm to the agent"), i.e. offers a wage scheme with slope one, making the agent residual claimant of all accruing profits. As the agent is risk neutral, he does not suffer from taking over the whole risk and, as he is residual claimant, his incentives are socially efficient. The solution in the case with a risk neutral but inequity averse agent looks different.

Proposition 3. If effort is not contractible and the agent is risk neutral with respect to wealth the optimal contract is strictly increasing with a slope between $1 / 2$ and 1 .

As the agent is inequity averse making him residual claimant would imply generically very unequal allocations and thus the degree of inequity being very volatile. Therefore the need to give high incentives and the desire to insure the agent against fluctuations in inequity work against each other and have to be balanced off in the optimal contract. However, the optimal contract can be further characterized and analyzing how the contract varies with $x$ reveals an interesting property.

\footnotetext{
10 Cf. Rogerson (1985) or Jewitt (1988) for conditions on distribution and utility functions to ensure the validity of the first order approach.
} 
Proposition 4. If the agent is risk neutral in wealth the optimal contract specifies a more equitable distribution of overall profit as the realized profit level increases.

Thus, inequity aversion is not only another friction but also delivers an additional incentive instrument.

As noted above in the standard model with a risk neutral agent it is optimal to implement the full information effort level also under moral hazard. Under inequity aversion this is not possible as we have just one instrument, the slope of the wage scheme, to balance the need to provide incentives and the desire to insure against varying degrees of inequity. ${ }^{11}$ If the principal gave higher powered incentives, this would lead to too inequitable allocations for which the agent would have to be compensated up front. Thus incentives are distorted downwards. However, it is not clear whether effort under inequity aversion will be lower than in the standard case as in some cases the agent will want to work harder as he also suffers if the principal is worse off than he is.

\subsubsection{Risk averse agents}

Now we approach the fully fledged problem and allow for risk aversion in the agent's preferences. Already in the standard model, where only the motive to insure the agent against fluctuations in wealth and the need to provide sufficient incentives are present, there is no clear cut prediction for the shape of the optimal incentive scheme, besides it being strictly increasing. This latter property is due to the monotone likelihood ratio property which implies that a higher profit level is informative with respect to the agent's effort choice. If we now turn to the analysis of our model, where we additionally have to take into account the agent's concern for equity, the situation gets even more complicated. Thus we cannot make a very sharp prediction either.

Proposition 5. If effort is not contractible and the agent is risk averse with respect to wealth the optimal contract is strictly increasing.

In this setting, one instrument has to balance off three countervailing forces and the shape of the scheme is determined by their interplay. We know that the scheme is increasing for two reasons: As in the standard model higher profit levels are informative signals and are therefore used to reward the agent. Additionally the agent also cares for an increasing wage scheme for reasons of fair sharing. The result from Proposition 4 concerning the degree of inequity for different outcomes does not generalize to the case of risk aversion. The desire to pay flat wages counteracts, and for sufficiently high degrees of risk aversion will overweigh, the tendency towards larger equality for higher payoffs, which would imply a slope of the wage function larger than $1 / 2$.

Exploiting the reasoning that the agent cares for an increasing wage scheme to ensure fair sharing allows us to state that, if the agent's concern for fairness is strong enough, we get an increasing wage scheme no matter whether high profit levels are informative or not.

Proposition 6. For any given signal quality there exists a value for $\alpha$, the agent's concern for equity, such that the monotone likelihood ratio property is not needed to ensure the optimal contract being strictly increasing in $x$.

It is instructive to further explore how the contract changes if $\alpha$ increases. It turns out that at some point the concern for equity becomes the dominant driving force for the structure of the contract and overrules all other motives. To the agent it is more important to ensure equity than to avoid risk and to the principal it is just too expensive to provide incentives beyond the equal split - as this would imply inequitable allocations at least sometimes. To compensate the agent for this risk then becomes prohibitively costly. An equal sharing rule solves this problem.

Proposition 7. If $\alpha$, the agent's concern for equity, increases, the optimal contract converges to $w(x)=1 / 2 x$, i.e. the equal split.

\subsection{Discussion of the assumptions}

Our formulation of the agent's utility function

$$
U_{A}=u(w(x))-c(e)-\alpha G([x-w(x)]-w(x))
$$

differs slightly from the original exposition of Fehr and Schmidt (1999), who also chose an additively separable but piecewise linear model of the form

$$
U_{i}\left(x_{i}\right)=x_{i}-\alpha_{i} \max \left\{x_{j}-x_{i}, 0\right\}-\beta_{i} \max \left\{x_{i}-x_{j}, 0\right\} .
$$

The first difference is that we also analyze the case where $u(w(x))$ is concave while Fehr and Schmidt (1999) focus on the risk neutral case, i.e. $u(w(x))=w(x)$. Though we solve our model for the risk neutral case, this is in the moral hazard

\footnotetext{
11 A formal exposition can be found in the working paper version of this paper which is available from the authors.
} 
context at hand probably not the most relevant special case as the interesting tradeoffs arise in the presence of risk aversion with respect to wealth.

The second difference is that we assume $G(\cdot)$ to be convex and continuously differentiable while they describe the disutility caused by inequitable outcomes in a piecewise linear way. Our formulation is analytically more convenient to handle. However, the basic driving force of our model is present in their model, too: The agent is risk averse towards lotteries over levels of inequity. While our convex formulation makes the agent also locally averse towards such lotteries, their piecewise linear formulation implies global aversion towards such lotteries. As long as the stochastic structure of the problem implies "large" lotteries (e.g. by normally distributed error terms) the "insurance-against-variations-in-inequity" intuition also works in a piecewise linear formulation.

In our approach the agent suffers disutility from the realization of inequity. An alternative would be to consider disutility arising from expected inequity. In that case no insurance against fluctuations in inequity would be needed and the principal could compensate the agent for expected inequity with a lump sum transfer. In our analysis we chose the first formulation in order to stay within the standard expected utility framework where the expectation is taken over utilities in the respective states of the world. Modeling inequity aversion over expected inequity, in contrast, would in general violate the independence axiom from von Neumann and Morgenstern expected utility theory, as shown by Kircher et al. (2009).

A third difference is less obvious. We analyze a model where the agent compares his monetary payoff to the principal's payoff. While the applications in Fehr and Schmidt (1999) are concerned with the analysis of experimental data where it makes sense to focus on final transfers, in our context one might reasonably argue, though there is no clear evidence for this argument, that the agent cares about his final transfer net of his disutility from effort $\left[w(x)-u^{-1}(c(e))\right]$. Our results qualitatively also hold for such a model. The resulting contract has similar properties as the one derived above and converges to $w(x)=\frac{1}{2}\left(x+u^{-1}(c(e))\right)$ for $\alpha \rightarrow \infty$ which implies that the agent wants to share costs, $u^{-1}(c(e))$, and benefits, $x$, of the interaction evenly. A formal exposition of this case can be found in the working paper version of this paper which is available from the authors. In order to strengthen the clarity of exposition we restrict our attention to the "simpler" case of comparing gross payoffs.

We can also relax the assumption that equality of payoffs is the reference point for the agent when he judges the fairness of an allocation. The qualitative nature of our results remains unchanged if we choose a formulation where the agent considers a fixed share $\frac{1}{k}$ of payoffs as fair or where the agent desires a fixed share of the net rent, i.e. payoffs net of agent's effort costs and any costs borne by the principal.

In contrast to standard contract theory models the assumption of an exogenously given outside option is not without loss of generality. Using it here basically implies that the agent no longer compares to the principal once he is not employed by him. Thus the reference group is restricted to the firm. ${ }^{12}$

One can ask whether focusing on the agent comparing himself to the principal and not to his peers is the appropriate thing to look at. ${ }^{13}$ However, as e.g. Ed Lazear (see Lazear, 1995, p. 49) puts it “... it is not obvious that workers should care more about harming other workers than they do about harming capital owners" when they contemplate shirking. ${ }^{14}$ Charness and Kuhn (2007) found in a labor market experiment where firms could employ workers that in evaluating the fairness of a situation it seems to be much more important for the agents how they fare compared to their (experimental) employer as compared to how they fare compared to the other workers in the experiment. In a similar vein one could ask whether the relevant principals are really firm owners (as in our model) or managers. Our model allows for this interpretation also, as long as this manager has discretion over the worker's pay and the manager's wealth depends on the agent's actions, e.g. via a stock option plan.

Finally, we assume that the principal has no concern for equity, but is selfish. We believe self-selection of profit maximizing types into being entrepreneurs is a strong argument for this modeling choice. However, we can allow for the principal to be inequity averse, too. Assuming inequity aversion on the principal's side only strengthens our results as now both parties have a preference for equitable distributions and are pushing for an equal sharing rule. ${ }^{15}$

\section{Extensions}

\subsection{Overdetermined contracts}

As pointed out above, inequity aversion is a reason why the agent is inherently interested in how the profits are divided - not only via the channel of its informative use in incentive provision. To show this consider the following setup: The firm's profit $\Pi$ can be separated into two parts $x$ and $y$, i.e. $\Pi=x+y$, where the distribution of $x$ depends on the effort $e$ exerted by the agent and $y$ is purely randomly distributed. In Appendix A.8 it is shown that contrary to Holmström's

\footnotetext{
12 This is empirically backed by Bewley (2002).

13 We deal with intra-worker comparisons in Section 3.3.

14 An example for the importance of such vertical comparisons are the massive quarrels at American Airlines in 2003 that took place after the company had imposed large wage cuts on the workers to avoid bankruptcy and it became known that the executives had not participated in these salary cuts. The unrest was explicitly pointed at this fact and American Airlines CEO Donald Carty had to resign.

15 A formal exposition of this case can be found in the working paper version of this paper which is available from the authors.
} 
(1979) well known sufficient statistics result, the optimal contract when the agent exhibits inequity aversion conditions on $y$, although this variable contains no information concerning the effort choice.

Proposition 8. With inequity averse agents the sufficient statistics result no longer applies. Optimal contracts may be overdetermined, i.e. contain non-relevant information with respect to effort choice.

The intuition is along the lines of Proposition 1. Profit serves not only as a signal whether or not the agent exerted enough effort, but is also important for the agent's utility as he has a concern for equitable distributions. As the agent compares his payoff to the principal's profit, $y$ is taken into account when equitability is judged. Therefore it has to be taken into account when the contract is written. If this is not done one ends up with too much inequity for which the agent has to be compensated upfront.

\subsection{Incomplete contracts}

In economic theory more attention has been paid to incomplete contracts than to overdetermined contracts. Our model can also account for incompleteness. Suppose we have the following situation. The principal has not only access to profit $x$ but also to another more direct performance measure $m$. The signal $m$ contains additional information on the agent's effort choice and should therefore - following Holmström's (1979) sufficient statistics result - be included in the optimal contract. In our set-up this is not necessarily the case if inequity aversion is very strong.

Corollary 2. If $\alpha$, the agent's concern for equity, converges to $\infty$ the optimal contract is uniquely defined by $w(x)=\frac{1}{2} x$ and additional informative signals are asymptotically disregarded. Thus the optimal contract is incomplete.

Note that this holds even for the extreme case where the signal $x$ is dominated in the sense of Second Order Stochastic Dominance by signal $\mathrm{m}$. The idea behind this result is again that the improved incentives cannot compensate for the fact that the agent now has to be compensated for less equitable allocations. Therefore it might be better to forego the chance to use superior performance measures and instead stick to profit in which the agent is intrinsically interested. This result holds more generally than only in the limit of $\alpha \rightarrow \infty$ if there are positive costs from including additional performance measures into the contract. Also, these additional performance measures would be generally underweighted in the optimal contract as compared to the case without inequity aversion. This is obviously not to say that with inequity aversion the basic logic of the sufficient statistics result no longer holds. With finite $\alpha$ and zero costs of contracting we can state an amended version of the sufficient statistics result: The optimal contract should depend exactly on all those variables that are informative w.r.t. to the chosen effort and that can help to provide insurance against variations in the degree of inequity.

\subsection{Team incentives}

Another natural extension is to analyze what happens if there is not only one agent but many as inequity aversion should be also important when agents interact with peers. Holmström (1982) analyzes the team problem and shows that the reason behind relative performance evaluation is not to induce competition between the agents but to filter out common shocks and hence expose the agents to less risk. Hence, the Holmström (1982) result is closely related to the sufficient statistics result. One implication is that an agent's pay conditions on another agent's output if and only if individual outputs are not independent.

This no longer holds if agents are inequity averse. Suppose there is one principal and two agents and, in order to make the argument as clear as possible, assume the agents' tasks are technologically independent. Each agent has to choose an effort level $e_{i}$ to influence a distribution function $f_{i}\left(x_{i} \mid e_{i}\right)$ where $x_{i}$ is the profit generated from agent $i$ 's project. Only the $x_{i}$ are contractible. The agents compare each others' gross payoff and the principal's payoff. The principal offers a contract $w_{i}\left(x_{1}, x_{2}\right)$ that can depend on both performance measures.

Agent 1's utility function takes the form

$$
\begin{aligned}
E U_{A 1}= & \int_{x_{1}}^{\bar{x}_{1}} \int_{x_{2}}^{\bar{x}_{2}} f_{1}\left(x \mid e_{1}\right) f_{2}\left(x \mid e_{2}\right)\left[u_{1}\left(w_{1}(\cdot)\right)-\alpha_{P 1} G\left(\left[\left(x_{1}+x_{2}\right)-\left[w_{2}(\cdot)+w_{1}(\cdot)\right]\right]-w_{1}(\cdot)\right)\right. \\
& \left.-\alpha_{A 1} H\left(w_{2}(\cdot)-w_{1}(\cdot)\right)\right] d x_{1} d x_{2}-c(e) .
\end{aligned}
$$

$\alpha_{P 1}$ measures how much weight he puts on the comparison towards the principal. The agent now suffers if his payoff $w_{1}(\cdot)$ differs from the principal's gross payoff $\left(x_{1}+x_{2}\right)$ net of total wage payments $\left(w_{2}(\cdot)+w_{1}(\cdot)\right)$. The disutility is - as in the basic model - captured by a convex function $G(\cdot)$. The agent also suffers if his payoff $w_{1}(\cdot)$ differs from his co-worker's payoff $w_{2}(\cdot)$. His concern for equity towards the other agent is weighted by $\alpha_{A 1}$ and measured by the convex function $H(\cdot)$. As before the agent is risk averse against variations in inequity towards his co-worker. The optimal contract takes care of this. 
Proposition 9. If agents are inequity averse there is a rationale for team incentives even if tasks are technologically independent.

Standard theory would suggest that if there is no technological link between agents' tasks and therefore no scope for relative performance evaluation to filter out common shocks, conditioning pay on other agents' output only adds noise. However, inequity averse agents have an intrinsic interest in other agents' performance. Conditioning pay on others' performance ensures that there is not too much inequity among the workers. This reduces the compensation agents demand for the risk of facing inequitable allocations and hence reduces the principal's costs. It is important to note that the optimal contract generally does not use relative performance evaluation, i.e. $\frac{w_{i}(\cdot)}{\partial x_{j}}<0$ but rather rewards agents jointly for high team output, i.e. $\frac{w_{i}(\cdot)}{\partial x_{j}}>0$. Relative performance evaluation features enter only when the initial pay is very uneven and serve to reduce payoff inequalities between the agents and the principal. It is again the tradeoff between optimal incentive provision and ensuring equity that drives this result. Focussing on the extreme case where inequity aversion is the sole driving force we get a very simple contractual structure.

Corollary 3. If agents' concern for equity among themselves becomes very large $\left(\alpha_{A} \rightarrow \infty\right)$ the optimal contract is a simple team contract basing each agent's pay solely on overall profit.

Note that this also implies wage compression as compared to the case when agents are not inequity averse, as now the pay of all agents moves together in the same direction.

\section{Relation to stylized facts}

Our first finding is, that the distribution of profits within a firm matters when agents are inequity averse. Lord and Hohenfeld (1979) report a study of major league baseball players who became "free agents"16 in one season where club owners had made use of an option to cut wages by $20 \%$. After this wage cut these players' - beforehand better-than-average - performance declined significantly, only to go up again after they had signed with new clubs. While standard theory would predict that performance should go up if the agent is looking for a new job to signal his high ability to the market, a model featuring inequity aversion is in line with this behavior. In our framework the declining performance can be seen as a means of the players to lower owner's profits in order to equalize shares of profits after the $20 \%$ cut. Mas (2006) shows that in the months after New Jersey police officers lose in final offer arbitration, arrest rates and average sentence length decline and crime reports rise relative to when they win. Final offer arbitration for police unions provides an opportunity to study the effect of how rents are shared, as the police officers either receive their requested wage or a lower one. Mas (2006) finds stronger declines in effort when the awarded wage is further from the police union's demand. Greenberg (1993) reports a field experiment in several plants of a firm where, after a wage cut, theft was measured. Only in those plants where wages were cut "with no good reason" theft went up significantly. ${ }^{17}$ Taking into account social preferences allows us to interpret the increase in theft as the employees stealing back what they view as their fair share. Along the same lines, Bewley (1999, p. 203 Tables 12.4 and 12.5) finds that the productivity loss in a firm after a wage cut is stronger in boom times, i.e. when firms' profits are high, than in a downturn when firms run losses. ${ }^{18}$ Finally, the presence of systematic and persistent inter industry wage differentials, i.e. an equally qualified worker in the same job earns significantly more in a higher profit industry, as documented in a meta study by Thaler (1989), whilst contradicting standard labor market theories, is consistent with fairness based theories of rent sharing. Blanchflower et al. (1996), Blanchflower and Oswald (1988), and Hildreth and Oswald (1997) find the same inter industry wage differentials and additionally the intertemporal effect that increased firm profits feed through to wage increases.

Our second result is the tendency towards linear and equal sharing rules implied by agents exhibiting inequity aversion. Taking a global perspective the most widespread incentive contracts are sharecropping contracts. As empirical studies by Bardhan and Rudra (1980), Bardhan (1984) and Young and Burke (2001) from India and Illinois find those are predominantly linear. Moreover $60 \%$ to $90 \%$ of these sharecropping contracts stipulate equal splitting rules. Allen (1985) notes that "metayage", the French word for sharecropping, actually means "dividing in half". The same holds for the Italian term "mezzadria". In contrast to this, standard economic theory predicts a much more complex and - from a practical point of view generally undetermined structure to be the optimal solution to the principal agent problem. ${ }^{19}$

Our model is also able to address the issue of completeness of contracts as optimal contracts might be incomplete, as informative but not profit related signals are excluded from contracts, or overdetermined, as non-informative but profit

\footnotetext{
16 A professional athlete who is free to sign a contract to play for any team.

17 The study controls for the efficiency wage argument that by the wage cut the value of retaining the job declines and thus the worker is more willing to take the risk of getting caught stealing and losing the job.

18 See Rotemberg (2003) for further examples along these lines.

19 See e.g. Holmström (1979) or Mirlees (1999). There have been only few attempts to explain the prominence of linear schemes in standard contracting models. Holmström and Milgrom (1987) consider a specific continuous time setting where the agent controls the drift rate of a Brownian motion and show that the optimal contract is linear in overall outcome. Innes (1990) assumes that the agent is risk neutral but wealth constrained. In this case the optimal contract makes the agent the residual claimant, i.e. takes a linear form, if the outcome exceeds a certain threshold. Finally, Bhattacharyya and Lafontaine (1995) find a linear sharing rule to be the optimal sharecropping contract in a specific setting with bilateral moral hazard.
} 
related signals are additionally included into contracts. While a huge literature deals with the causes and consequences of contractual incompleteness, there has been less focus on overdetermination of contracts. There are several sources showing the widespread use of employee stock and stock options also for lower tier workers. For example CISCO Systems has such schemes for every single employee and at Starbucks even part time workers are entitled to such schemes. A 1987 US Government Accounting Office survey shows that $54 \%$ of non-unionized and $39 \%$ of unionized Fortune 1000 firms had firm wide profit sharing plans in place. Knez and Simester (2001) report the enormous success of Continental Airlines that introduced a firmwide profit sharing scheme. Their study showed that the increases in productivity can be largely accounted for by this profit sharing plan. These findings fit in our analysis as inequity averse workers are inherently interested in profit sharing plans - even if these stock and stock options are not good performance measures as a single lower tier worker's influence on the stock price is presumably negligible. ${ }^{20}$ These findings also hold for top tier employees. Bertrand and Mullainathan (2001) find that CEO income reacts equally strongly to "lucky" and to "general" profits, where lucky profits are those not controllable by the CEO. ${ }^{21}$

Finally our analysis of team incentives fits the studies by Bandiera et al. (2005) and Agell (2004). Bandiera et al. (2005) present a field experiment where they were able to alter the incentive structure for field workers in a UK farm. They find that incentives based on relative performance measures perform worse than incentives based on individual measures of performance. They argue that an effort dampening effect due to fairness or reciprocity motives - caused by the negative externality of own effort generated by the relative performance contracts - is a possible explanation for their result. Agell (2004) finds that there are systematic differences in pay structure between large and small firms, with small firms, where we would expect social comparisons to be more important, having less competitive schemes (no relative performance evaluation, more wage compression) in place.

\section{Conclusion}

Our analysis shows that incorporating social preferences into the analysis of optimal incentives can improve our understanding of real world incentive schemes. If agents exhibit an aversion towards inequitable distributions the optimal contract has to balance the agent's concern for insurance and fairness and the principal's desire to provide adequate incentives. The agent's concern for equity adds a rationale for linear sharing rules and it adds an additional incentive instrument: the agent can be rewarded for better performance not only by paying more, but also by paying more equitably. Due to the inherent interest in the distribution of profits, Holmström's sufficient statistics result is violated and optimal contracts may be either overdetermined or even incomplete. Along the same lines of reasoning we get a rationale for team incentives even if tasks are independent. Thus, introducing inequity aversion into the analysis of contracting problems offers a plausible explanation for an array of empirical phenomena.

However, our analysis is only a first step and there remain many open questions to be tackled. It is important to understand what determines the reference group for social comparison processes. As relative income comparisons have the above described effects on incentives and effort it is important to control to whom agents compare such that ill-led comparisons do not lead to detrimental outcomes. Taking these arguments seriously may help us to gain some additional insights into what determines the boundaries of the firm. The above described social comparisons may render it impractical to set up a new division in-house, if this division requires the hiring of very highly paid individuals that are then included into the reference group for social comparisons. In circumstances like this it may be more reasonable to set up a spin-off company to accommodate this new division.

Another interesting question is whether there is sorting with respect to the "fairness type" in the labor market. Casciaro (2001) reports that people can detect whether others have social feelings towards them and O'Reilly and Pfeffer (1995) and Oliva and Gittell (2002) provide details about Southwest Airlines that hires only after checking for social type.

Finally, if social preferences are important and matter for effort exertion and incentive provision it would naturally be of importance for firms to be able to alter them. Milgrom and Roberts (1992) already point out that a large share of companies' Human Resource Management activities is targeted at shaping employees preferences. While this question is central to researchers in Organizational Behavior or Human Resource Management, it has received only little attention by economists. $^{22} \mathrm{~A}$ related issue is how an interaction is perceived by the agent. What is the relevant time horizon, what are the limits of a relation?

\footnotetext{
20 Moreover, stockholding in the own company is bad from a portfolio composition perspective as it is highly correlated with risks to an employee's (firm specific) human capital.

21 Particularly interesting in our context is their finding that in firms with "anti-takeover-clauses" (that protect the CEO) not only the CEO earns more, but also all other employees. So whilst the finding on CEO income could be interpreted a la Bebchuk and Fried (2003) as the CEO - who basically can freely set his own pay - just diverting money from the shareholders to herself, the latter finding is very much in line with a theory of an inequity averse workforce that demands to be treated fairly.

22 Rotemberg (1994) is one exception, although his focus is different.
} 


\section{Appendix A}

\section{A.1. Proof of Proposition 1}

The principal's problem is given by

$$
\begin{aligned}
& \max _{e, w(x)} E U_{P}=\int_{\underline{x}}^{\bar{x}} f(x \mid e)[x-w(x)] d x \\
& \text { s.t. } \quad(P C) \quad E U_{A}=\int_{\underline{x}}^{\bar{x}} f(x \mid e)[u(w(x))-\alpha G(x-2 w(x))] d x-c(e) \geqslant \bar{U}
\end{aligned}
$$

and the Lagrangian takes the form

$$
\begin{aligned}
L= & \int_{\underline{x}}^{\bar{x}} f(x \mid e)[x-w(x)] d x \\
& -\lambda\left[\bar{U}-\int_{\underline{x}}^{\bar{x}} f(x \mid e)[u(w(x))-\alpha G(x-2 w(x))] d x+c(e)\right] .
\end{aligned}
$$

The first order condition is then given by

$$
\frac{\partial L}{\partial w(x)}=-f(x \mid e)+\lambda f(x \mid e) u^{\prime}(w(x))+\lambda f(x \mid e) 2 \alpha G^{\prime}(x-2 w(x))=0 .
$$

Dividing by $f(x \mid e)$ and rearranging yields

$$
\frac{1-\lambda u^{\prime}(w(x))}{\lambda 2 \alpha}=G^{\prime}(x-2 w(x)) .
$$

Note that for risk neutral agents $u^{\prime}(w(x))$ is a constant: $u^{\prime}(w(x))=k$

$$
\begin{aligned}
& \frac{1-\lambda k}{\lambda 2 \alpha}=G^{\prime}(x-2 w(x)) \Rightarrow \\
& G^{\prime}(x-2 w(x))=k^{\prime} \quad \text { (a constant) } \Leftrightarrow \\
& x-2 w(x)=k^{\prime \prime} \quad \text { (also a constant) due to } G^{\prime \prime}(\cdot)>0 \quad \Leftrightarrow \\
& w(x)=\frac{k^{\prime \prime}}{2}+\frac{x}{2} .
\end{aligned}
$$

\section{A.2. Proof of Proposition 2}

The principal's problem, the Lagrangian and the first order condition are as in Proposition 1 and can be rewritten as

$$
-1+\lambda\left[u^{\prime}(w(x))+2 \alpha G^{\prime}(x-2 w(x))\right]=0 .
$$

Totally differentiating this expression yields

$$
\begin{aligned}
& 0=w^{\prime}(x) u^{\prime \prime}(w(x))+2 \alpha G^{\prime \prime}(\cdot)\left(1-2 w^{\prime}(x)\right), \\
& w^{\prime}(x)=\frac{\left[2 \alpha G^{\prime \prime}(\cdot)\right]-\left[\frac{1}{2} u^{\prime \prime}(w(x))-\frac{1}{2} u^{\prime \prime}(w(x))\right]}{\left(4 \alpha G^{\prime \prime}(\cdot)-u^{\prime \prime}(w(x))\right)} .
\end{aligned}
$$

Note, that $w^{\prime}>0$ holds,

$$
\begin{aligned}
w^{\prime}(x)= & \frac{2 \alpha G^{\prime \prime}(\cdot)-\frac{1}{2} u^{\prime \prime}(w(x))}{4 \alpha G^{\prime \prime}(\cdot)-u^{\prime \prime}(w(x))} \\
& +\frac{\frac{1}{2} u^{\prime \prime}(w(x))}{4 \alpha G^{\prime \prime}(\cdot)-u^{\prime \prime}(w(x))}, \\
w^{\prime}(x)= & \frac{1}{2}+\frac{u^{\prime \prime}(w(x))}{\left(8 \alpha G^{\prime \prime}(\cdot)-2 u^{\prime \prime}(w(x))\right)}
\end{aligned}
$$

where $\frac{u^{\prime \prime}(w(x))}{\left(8 \alpha G^{\prime \prime}(\cdot)-2 u^{\prime \prime}(w(x))\right)}<0$ as $u^{\prime \prime}(w(x))<0$. Thus $0<w^{\prime}(x)<\frac{1}{2}$ holds. 


\section{A.3. Proof of Proposition 3}

Now the principal has to pay attention to the agent's incentive constraint. Thus his optimization problem is given by

$$
\begin{aligned}
& \max _{w(x)} E U_{P}=\int_{\underline{x}}^{\bar{x}} f(x \mid e)[x-w(x)] d x \\
& \text { s.t. } \quad(\mathrm{PC}) \quad E U_{A}=\int_{\underline{x}}^{\bar{x}} f(x \mid e)[u(w(x))-\alpha G(x-2 w(x))] d x-c(e) \geqslant \bar{U} \text {, } \\
& \text { (IC) } e \in \arg \max _{\bar{e}} E U_{A}=\int_{\underline{x}}^{\bar{x}} f(x \mid \tilde{e})[u(w(x))-\alpha G(x-2 w(x))] d x-c(\tilde{e}) \text {, } \\
& \left(\mathrm{IC}^{\prime}\right) \quad 0=\int_{\underline{x}}^{\bar{x}} f_{e}(x \mid e)[u(w(x))-\alpha G(x-2 w(x))] d x-c^{\prime}(e)
\end{aligned}
$$

where the Lagrangian takes the form

$$
\begin{aligned}
L= & \int_{\underline{x}}^{\bar{x}} f(x \mid e)[x-w(x)] d x \\
& -\lambda\left[\bar{U}-\int_{\underline{x}}^{\bar{x}} f(x \mid e)[u(w(x))-\alpha G(x-2 w(x))] d x+c(e)\right] \\
& -\mu\left[0-\int_{\underline{x}}^{\bar{x}} f_{e}(x \mid e)[u(w(x))-\alpha G(x-2 w(x))] d x+c^{\prime}(e)\right] .
\end{aligned}
$$

The resulting first order condition can be divided by $f(x \mid e)$ and rewritten to

$$
\left[\lambda+\mu \frac{f_{e}(x \mid e)}{f(x \mid e)}\right]\left[u^{\prime}(w(x))+2 \alpha G^{\prime}(x-2 w(x))\right]-1=0 .
$$

Totally differentiating with respect to $x$ yields

$$
\begin{array}{r}
0=\left[u^{\prime \prime}(w(x)) w^{\prime}(x)+2 \alpha G^{\prime \prime}(x-2 w(x))\left(1-2 w^{\prime}(x)\right)\right] \\
+\mu \frac{\left(\frac{f_{e}(x \mid e)}{f(x \mid e)}\right)^{\prime}}{\left[\lambda+\mu \frac{f_{e}(x \mid e)}{f(x \mid e)}\right]}\left[u^{\prime}(w(x))+2 \alpha G^{\prime}(x-2 w(x))\right]
\end{array}
$$

where $\left(\frac{f_{e}(x \mid e)}{f(x \mid e)}\right)^{\prime}$ denotes the derivative of the likelihood ratio $\left(\frac{f_{e}(x \mid e)}{f(x \mid e)}\right)$ with respect to $x$. Note that $\left(\frac{f_{e}(x \mid e)}{f(x \mid e)}\right)^{\prime}>0$ is implied by the monotone likelihood ratio property and that due to risk neutrality $u^{\prime \prime}(w(x))=0$ and $u^{\prime}(w(x))$ is a constant. Thus we get

$$
w^{\prime}(x)=\frac{1}{2}+\frac{\mu\left(\frac{f_{e}(x \mid e)}{f(x \mid e)}\right)^{\prime} \frac{\left[u^{\prime}(w(x))+2 \alpha G^{\prime}(x-2 w(x))\right]}{\left[\lambda+\mu \frac{f_{e}(x \mid e)}{f(x \mid e)}\right]}}{4 \alpha G^{\prime \prime}(x-2 w(x))}
$$

where all terms but

$$
\frac{\left[u^{\prime}(w(x))+2 \alpha G^{\prime}(x-2 w(x))\right]}{\left[\lambda+\mu \frac{f_{e}(x \mid e)}{f(x \mid e)}\right]}
$$

are obviously positive. To ensure that

$$
\frac{\left[u^{\prime}(w(x))+2 \alpha G^{\prime}(x-2 w(x))\right]}{\left[\lambda+\mu \frac{f_{e}(x \mid e)}{f(x \mid e)}\right]}
$$


is positive, too, check again the first order condition:

$$
\begin{aligned}
& {\left[\lambda+\mu \frac{f_{e}(x \mid e)}{f(x \mid e)}\right]\left[u^{\prime}(w(x))+2 \alpha G^{\prime}(x-2 w(x))\right]-1=0 \Leftrightarrow} \\
& {\left[u^{\prime}(w(x))+2 \alpha G^{\prime}(x-2 w(x))\right]=\frac{1}{\left[\lambda+\mu \frac{f_{e}(x \mid e)}{f(x \mid e)}\right]} .}
\end{aligned}
$$

This is only possible if the both terms $\left[u^{\prime}(w(x))+2 \alpha G^{\prime}(x-2 w(x))\right]$ and $\left[\lambda+\mu \frac{f_{e}(x \mid e)}{f(x \mid e)}\right]$ have the same sign. Thus all terms from above are strictly positive and $w^{\prime}(x)>\frac{1}{2}$ holds. $w^{\prime}(x)<1$ is implied by our assumptions that the agent can boost the profits. If at some point $w^{\prime}(x)>1$, it would pay for the agent to inject own funds to increase his earnings.

\section{A.4. Proof of Proposition 4}

Remember that the first order condition can be written as

$$
G^{\prime}(x-2 w(x))=\frac{1}{2 \alpha}\left[\frac{1}{\left[\lambda+\mu \frac{f_{e}(x \mid e)}{f(x \mid e)}\right]}-u^{\prime}(w(x))\right] .
$$

When the agent is risk neutral $u^{\prime}(w(x))$ is constant. If $x$ increases, $\frac{f_{e}(x \mid e)}{f(x \mid e)}$ increases (as we assumed the monotone likelihood ratio property) and, as $u^{\prime}(w(x))$ is not affected, the whole latter term decreases. Thus the absolute value of $G^{\prime}(\cdot)$ decreases, in turn implying less inequity.

\section{A.5. Proof of Proposition 5}

The principal's problem, the Lagrangian and the first order condition are as in the proof of Proposition 3 , so that the latter is

$$
\left[\lambda+\mu \frac{f_{e}(x \mid e)}{f(x \mid e)}\right]\left[u^{\prime}(w(x))+2 \alpha G^{\prime}(x-2 w(x))\right]-1=0 .
$$

Totally differentiating this expression with respect to $x$ yields

$$
\begin{aligned}
0= & {\left[\lambda+\mu \frac{f_{e}(x \mid e)}{f(x \mid e)}\right]\left[u^{\prime \prime}(w(x)) w^{\prime}(x)+2 \alpha G^{\prime \prime}(x-2 w(x))\left(1-2 w^{\prime}(x)\right)\right] } \\
& +\mu\left(\frac{f_{e}(x \mid e)}{f(x \mid e)}\right)^{\prime}\left[u^{\prime}(w(x))+2 \alpha G^{\prime}(x-2 w(x))\right]
\end{aligned}
$$

which can be rearranged to

$$
\begin{aligned}
w^{\prime}(x)= & \frac{2 \alpha G^{\prime \prime}(x-2 w(x))}{\left[4 \alpha G^{\prime \prime}(x-2 w(x))-u^{\prime \prime}(w(x))\right]} \\
& +\frac{\mu\left(\frac{f_{e}(x \mid e)}{f(x \mid e)}\right)^{\prime}\left[u^{\prime}(w(x))+2 \alpha G^{\prime}(x-2 w(x))\right]}{\left[\lambda+\mu \frac{f_{e}(x \mid e)}{f(x \mid e)}\right]\left[4 \alpha G^{\prime \prime}(x-2 w(x))-u^{\prime \prime}(w(x))\right]} .
\end{aligned}
$$

As all terms are strictly positive (see the proof of Proposition 3 which shows that the last term has to be positive) it holds that $w^{\prime}(x)>0$.

\section{A.6. Proof of Proposition 6}

Taking the limit for $\alpha \rightarrow \infty$ in the proof of Proposition 5 implies the proposition as the slope of $\frac{1}{2}$ is independent of the signal quality.

\section{A.7. Proof of Proposition 7}

We can rewrite the first order condition from the proof of Proposition 3 as

$$
\frac{1}{\left[\lambda+\mu \frac{f_{e}(x \mid e)}{f(x \mid e)}\right]}=2 \alpha G^{\prime}(x-2 w(x))+u^{\prime}(w(x)) .
$$


Now convergence to $1 / 2 x$ implies that with an increase in $\alpha$ for any given $\tilde{x}, w(\tilde{x})$ has to be increased (decreased) if $x-2 w(x)>0(x-2 w(x)<0)$. Remember that

$$
\begin{aligned}
& G^{\prime}>0 \text { for } x-2 w(x)>0, \\
& G^{\prime}<0 \text { for } x-2 w(x)<0 .
\end{aligned}
$$

The first order condition has to hold in any point. The left hand side is, given $x$, a constant. For $x-2 w(x)>0$, i.e. a situation where $w(x)<1 / 2 x$, an increase in $\alpha$ has to be balanced by an increase in $w(x)$. This decreases $G^{\prime}(x-2 w(x))$ and decreases $u^{\prime}(w(x))$. For $x-2 w(x)<0$, i.e. a situation where $w(x)>1 / 2 x$, an increase in $\alpha$ has to be balanced by a decrease in $w(x)$. This increases $G^{\prime}(x-2 w(x))$ - which is negative - and increases $u^{\prime}(w(x))$.

To see that the convergence is in fact complete, consider the limit of $\alpha \rightarrow \infty$. Remember the participation constraint:

$$
\text { s.t. } \quad(\mathrm{PC}) \quad E U_{A}=\int_{\underline{x}}^{\bar{x}} f(x \mid e)[u(w(x))-\alpha G(x-2 w(x))] d x-c(e) \geqslant \bar{U} .
$$

Dividing the whole expression by $\alpha$ we get

$$
\int_{\underline{x}}^{\bar{x}} f(x \mid e)\left[\frac{u(w(x))}{\alpha}-G(x-2 w(x))\right] d x-\frac{c(e)}{\alpha} \geqslant \frac{\bar{U}}{\alpha} .
$$

For the limit of $\alpha \rightarrow \infty$ the relevant constraint now is

$$
\int_{\underline{x}}^{\bar{x}} f(x \mid e)[-G(x-2 w(x))] d x \geqslant 0 .
$$

Note that this can only be satisfied if $G(\cdot)=0$ which in turn is only true for $w(x)=\frac{1}{2} x$.

\section{A.8. Proof of Proposition 8}

Suppose the firms' profit $\Pi$ can be separated into two parts $x$ and $y$, i.e. $\Pi=x+y$. While the distribution $f(x \mid e)$ of $x$ depends on the effort $e$ exerted by the agent, $y$ is purely randomly distributed and its density is given by $g(y)$. To show that the sufficient statistics result does not apply when the agent exhibits inequity aversion consider the principal's optimization problem

$$
\begin{aligned}
& \max \quad E U_{P}=\int_{\underline{x}}^{\bar{x}} f(x \mid e) x d x+\int_{\underline{y}}^{\bar{y}} g(y) y d y-\int_{\underline{x}}^{\bar{x}} \int_{\underline{y}}^{\bar{y}} w(x, y) f(x \mid e) g(y) d x d y \\
& \text { s.t. } \quad \text { (PC) } \bar{U} \leqslant \int_{\underline{x}}^{\bar{x}} \int_{\underline{y}}^{\bar{y}}[u(w(x, y))-\alpha G(x+y-2 w(x, y))] f(x \mid e) g(y) d x d y-c(e), \\
& \text { (IC) } e \in \arg \max _{\tilde{e}} \int_{\underline{x}}^{\bar{x}} \int_{\underline{y}}^{\bar{y}}[u(w(x, y))-\alpha G(x+y-2 w(x, y))] f(x \mid \tilde{e}) g(y) d x d y-c(\tilde{e}), \\
& \text { (IC') } 0=\int_{\underline{x}}^{\bar{x}} \int_{\underline{y}}^{\bar{y}} f_{e}(x \mid e) g(y)[u(w(x, y))-\alpha G(x+y-2 w(x, y))] d x d y-c_{e}(e)
\end{aligned}
$$

where $g(y)$ is the density function for $y$, the random part of the profit.

The Lagrangian is given by

$$
L=\int_{\underline{x}}^{\bar{x}} f(x \mid e) x d x+\int_{\underline{y}}^{\bar{y}} g(y) y d y-\int_{\underline{x}}^{\bar{x}} \int_{\underline{y}}^{\bar{y}} w(x, y) f(x \mid e) g(y) d x d y
$$




$$
\begin{aligned}
& -\lambda\left[\bar{U}-\int_{\underline{x}}^{\bar{x}} \int_{\underline{y}}^{\bar{y}}[u(w(x, y))-\alpha G(x+y-2 w(x, y))] f(x \mid e) g(y) d x d y+c(e)\right] \\
& -\mu\left[0-\int_{\underline{x}}^{\bar{x}} \int_{\underline{y}}^{\bar{y}} f_{e}(x \mid e) g(y)[u(w(x, y))-\alpha G(x+y-2 w(x, y))] d x d y+c_{e}(e)\right] .
\end{aligned}
$$

The first order condition for the principal's optimization problem has the following form

$$
-1+\lambda\left[u^{\prime}(w(x, y))+2 \alpha G^{\prime}(\cdot)\right]+\mu \frac{f_{e}(x \mid e)}{f(x \mid e)}\left[u^{\prime}(w(x, y))+2 \alpha G^{\prime}(\cdot)\right]=0
$$

An application of the implicit function theorem yields

$$
\frac{\partial w}{\partial y}=\frac{\alpha G^{\prime \prime}(\cdot)}{4 \alpha G^{\prime \prime}(\cdot)-u^{\prime \prime}(w(x, y))}>0 \quad \forall \alpha \neq 0 .
$$

As $w$ depends on $y$, which does not contain any information about the agent's effort choice the sufficient statistics result does not apply. Not surprisingly, for $\alpha=0$, i.e. a purely selfish agent, the sufficient statistics result applies again, as then $w_{y}(x, y)=0$ holds.

\section{A.9. Proof of Corollary 2}

The proof follows immediately from the proof of Proposition 7. For $\alpha \rightarrow \infty$ the optimal contract is uniquely determined by $w(x)=\frac{1}{2} x$, no matter whether effort is contractible or not. Thus effort is disregarded.

\section{A.10. Proof of Proposition 9}

For the case with two agents the utility of agent 1 is given by

$$
\begin{aligned}
E U_{A 1}= & \int_{\underline{x}_{1}}^{\bar{x}_{1}} \int_{\underline{x}_{2}}^{\bar{x}_{2}} f_{1}\left(x_{1} \mid e_{1}\right) f_{2}\left(x_{2} \mid e_{2}\right)\left[u_{1}\left(w_{1}(\cdot)\right)-\alpha_{P 1} G\left(\left(x_{1}+x_{2}-w_{2}(\cdot)-w_{1}(\cdot)\right)-w_{1}(\cdot)\right)\right. \\
& \left.-\alpha_{A 1} H\left(w_{2}(\cdot)-w_{1}(\cdot)\right)\right] d x_{1} d x_{2}-c(e) \\
= & \int_{\underline{x_{1}}}^{\bar{x}_{1}} \int_{\bar{x}_{2}}^{\bar{x}_{2}} f_{1}\left(x_{1} \mid e_{1}\right) f_{2}\left(x_{2} \mid e_{2}\right)\left[u_{1}\left(w_{1}(\cdot)\right)-\alpha_{P 1} G\left(x_{1}+x_{2}-w_{2}(\cdot)-2 w_{1}(\cdot)\right)\right. \\
& \left.-\alpha_{A 1} H\left(w_{2}(\cdot)-w_{1}(\cdot)\right)\right] d x_{1} d x_{2}-c(e)
\end{aligned}
$$

where $w_{1}(\cdot)=w_{1}\left(x_{1}, x_{2}\right)$ and $w_{1}(\cdot)=w_{2}\left(x_{1}, x_{2}\right)$.

Thus the principal's problem takes the form

$$
\begin{aligned}
& \max _{e, w(x)} E U_{P}=\int_{\underline{x_{1}}}^{\bar{x}_{1}} \int_{\underline{x_{2}}}^{\bar{x}_{2}} f_{1}\left(x_{1} \mid e_{1}\right) f_{2}\left(x_{2} \mid e_{2}\right)\left[x_{1}+x_{2}-w_{2}(\cdot)-w_{1}(\cdot)\right] d x_{1} d x_{2} \\
& \text { s.t. } \quad(\mathrm{PC}) \quad E U_{A i}=\int_{\underline{x_{1}}}^{\bar{x}_{1}} \int_{\underline{x}_{2}}^{\bar{x}_{2}} f_{i}\left(x_{i} \mid e_{i}\right) f_{j}\left(x_{j} \mid e_{j}\right)\left[u_{i}\left(w_{i}(\cdot)\right)-\alpha_{P i} G(\cdot)-\alpha_{A i} H(\cdot)\right] d x_{1} d x_{2}-c\left(e_{i}\right) \geqslant \bar{U}, \\
& i, j \in\{1,2\}, i \neq j \text {, } \\
& \text { (IC) } e \in \arg \max _{e} E U_{A i}=\int_{\underline{x_{1}}}^{\bar{x}_{1}} \int_{x_{2}}^{\bar{x}_{2}} f_{i}\left(x_{i} \mid e_{i}\right) f_{j}\left(x_{j} \mid e_{j}\right)\left[u_{i}\left(w_{i}(\cdot)\right)-\alpha_{P i} G(\cdot)-\alpha_{A i} H(\cdot)\right] d x_{1} d x_{2}-c\left(e_{i}\right) \text {, } \\
& i, j \in\{1,2\}, i \neq j \text {, } \\
& \left(\mathrm{IC}^{\prime}\right) \quad 0=\int_{\underline{x_{1}}}^{\bar{x}_{1}} \int_{\underline{x_{2}}}^{\bar{x}_{2}} f_{i_{e_{i}}}\left(x_{i} \mid e_{i}\right) f_{j}\left(x_{j} \mid e_{j}\right)\left[u_{i}\left(w_{i}\left(x_{i}, x_{j}\right)\right)-\alpha_{P i} G(\cdot)-\alpha_{A i} H(\cdot)\right] d x_{1} d x_{2}-c^{\prime}\left(e_{i}\right), \\
& i, j \in\{1,2\}, i \neq j \text {, }
\end{aligned}
$$


and the Lagrangian becomes

$$
\begin{aligned}
L= & \int_{\underline{x_{1}}}^{\bar{x}_{1}} \int_{\underline{x}_{2}}^{\bar{x}_{2}} f_{1}\left(x_{1} \mid e_{1}\right) f_{2}\left(x_{2} \mid e_{2}\right)\left[x_{1}+x_{2}-w_{2}\left(x_{1}, x_{2}\right)-w_{1}\left(x_{1}, x_{2}\right)\right] d x_{1} d x_{2} \\
& -\lambda_{1}\left[\bar{U}-\int_{x_{1}}^{\underline{x_{1}}} \int_{x_{2}}^{\bar{x}_{1}} f_{1}\left(x_{1} \mid e_{1}\right) f_{2}\left(x_{2} \mid e_{2}\right)\left[u_{1}\left(w_{1}\left(x_{1}, x_{2}\right)\right)-\alpha_{P 1} G(\cdot)-\alpha_{A 1} H(\cdot)\right] d x_{1} d x_{2}+c\left(e_{1}\right)\right] \\
& -\lambda_{2}\left[\bar{U}-\int_{x_{1}}^{\bar{x}_{1}} \int_{x_{2}}^{\bar{x}_{2}} f_{1}\left(x_{1} \mid e_{1}\right) f_{2}\left(x_{2} \mid e_{2}\right)\left[u_{2}\left(w_{2}\left(x_{1}, x_{2}\right)\right)-\alpha_{P 2} G(\cdot)-\alpha_{A 2} H(\cdot)\right] d x_{1} d x_{2}+c\left(e_{2}\right)\right] \\
& -\mu_{1}\left[0-\int_{x_{1}}^{\bar{x}_{1}} \int_{x_{2}}^{\bar{x}_{2}} f_{1_{e_{1}}}\left(x_{1} \mid e_{1}\right) f_{2}\left(x_{2} \mid e_{2}\right)\left[u_{1}\left(w_{1}\left(x_{1}, x_{2}\right)\right)-\alpha_{P 1} G(\cdot)-\alpha_{A 1} H(\cdot)\right] d x_{1} d x_{2}+c^{\prime}\left(e_{1}\right)\right] \\
& -\mu_{2}\left[0-\int_{x_{1}}^{\bar{x}_{1}} \int_{\bar{x}_{2}}^{\bar{x}_{2}} f_{2_{e_{2}}}\left(x_{2} \mid e_{2}\right) f_{1}\left(x_{1} \mid e_{1}\right)\left[u_{2}\left(w_{2}\left(x_{1}, x_{2}\right)\right)-\alpha_{P 2} G(\cdot)-\alpha_{A 2} H(\cdot)\right] d x_{1} d x_{2}+c^{\prime}\left(e_{2}\right)\right] .
\end{aligned}
$$

Dividing the first order condition by $f_{1}(\cdot) f_{2}(\cdot)$ and rearranging yields

$$
1=\left[\lambda_{1}+\mu_{1} \frac{f_{1}^{\prime}(\cdot)}{f_{1}(\cdot)}\right]\left[u_{1}^{\prime}(\cdot)+2 \alpha_{P 1} G^{\prime}(\cdot)+\alpha_{A 1} H^{\prime}(\cdot)\right]+\left[\lambda_{2}+\mu_{2} \frac{f_{2}^{\prime}(\cdot)}{f_{2}(\cdot)}\right]\left[\alpha_{P 2} G^{\prime}(\cdot)-\alpha_{A 2} H^{\prime}(\cdot)\right] .
$$

Differentiating this expression with respect to $x_{2}$, simplifying and solving for $\frac{\partial w_{1}(\cdot)}{\partial x_{2}}$ gives

$$
\begin{aligned}
\frac{\partial w_{1}(\cdot)}{\partial x_{2}}= & \frac{\left[\lambda_{1}+\mu_{1} \frac{f_{1}^{\prime}(\cdot)}{f_{1}(\cdot)}\right]\left[2 \alpha_{P 1} G^{\prime \prime}(\cdot)\left[1-\frac{\partial w_{2}(\cdot)}{\partial x_{2}}\right]+\frac{\partial w_{2}(\cdot)}{\partial x_{2}} \alpha_{A 1} H^{\prime \prime}(\cdot)\right]}{K} \\
& +\frac{\left[\lambda_{2}+\mu_{2} \frac{f_{2}^{\prime}}{f_{2}}\right]\left[\alpha_{P 2} G^{\prime \prime}(\cdot)\left[1-2 \frac{\partial w_{2}(\cdot)}{\partial x_{2}}\right]+\frac{\partial w_{2}(\cdot)}{\partial x_{2}} \alpha_{A 2} H^{\prime \prime}(\cdot)\right]}{K} \\
& +\frac{\mu_{2} \frac{\partial\left[\frac{f_{2}^{\prime}}{\partial x_{2}}\right]}{\partial x_{2}}\left[\alpha_{P 2} G^{\prime}(\cdot)-\alpha_{A 2} H^{\prime}(\cdot)\right]}{K}
\end{aligned}
$$

where $K$ is defined as

$$
K=\left[\lambda_{2}+\mu_{2} \frac{f_{2}^{\prime}}{f_{2}}\right]\left[\alpha_{P 2} G^{\prime \prime}(\cdot)+\alpha_{A 2} H^{\prime \prime}(\cdot)\right]-\left[\lambda_{1}+\mu_{1} \frac{f_{1}^{\prime}}{f_{1}}\right]\left[u_{1}^{\prime \prime}(\cdot)-4 \alpha_{P 1} G^{\prime \prime}(\cdot)-\alpha_{A 1} H^{\prime \prime}(\cdot)\right] .
$$

Note that $K>0$ as $G^{\prime \prime}(\cdot), H^{\prime \prime}(\cdot)$ are strictly positive by assumption and $u^{\prime \prime}(\cdot)$ is strictly negative. Furthermore we know that $\frac{\partial w_{2}(\cdot)}{\partial x_{2}}$ is strictly between 0 and 1 . First note that $\frac{\partial w_{1}(\cdot)}{\partial x_{2}}$ is generically different from 0 . Furthermore we see that $\frac{\partial w_{1}(\cdot)}{\partial x_{2}}>0$ holds most of the time. Only when the wages are such that agent 1 is already far better off than agent 2 , i.e. $H^{\prime}(\cdot)$ very high, or when the principal is worse off than the agents, i.e. $G^{\prime}(\cdot)$ very negative and $\frac{\partial w_{2}(\cdot)}{\partial x_{2}}$ larger than $\frac{1}{2}$, the expression may be negative and $w_{1}(\cdot)$ decreases in order to reduce inequality.

\section{A.11. Proof of Corollary 3}

As in the proof of Proposition 7 we divide the participation constraint by $\alpha_{A}$ and consider the relevant constraint in the limit of $\alpha_{A} \rightarrow \infty$

$$
\int_{\underline{x_{1}}}^{\bar{x}_{1}} \int_{\underline{x_{2}}}^{\bar{x}_{2}} f_{1}\left(x_{1} \mid e_{1}\right) f_{2}\left(x_{2} \mid e_{2}\right)[-H(\cdot)] d x_{1} d x_{2} \geqslant 0
$$

which only holds for $H(\cdot)=0$ which in turn is only true for $w_{1}(\cdot)=w_{2}(\cdot)$. Thus the two $H$ terms drop out of the optimization problem and the principal maximizes the same problem as in the situation with one agent under the constraint that $w_{1}(\cdot)=w_{2}(\cdot) \forall x_{i}, x_{j}$. From the above analysis we know that the optimal contract will be increasing and thus we have a simple team performance contract. 


\section{References}

Agell, J., 2004. Why are small firms different? Managers' views. Scand. J. Econ. 106 (3), 437-452.

Allen, F., 1985. On the fixed nature of sharecropping contracts. Econ. J. 95, 30-48.

Bandiera, O., Barankay, I., Rasul, I., 2005. Social preferences and the response to incentives: evidence from personnel data. Quart. J. Econ. 120, 917-962.

Bardhan, P., 1984. Land, Labor, and Rural Poverty. Columbia University Press, New York, NY.

Bardhan, P., Rudra, A., 1980. Terms and conditions of sharecropping contracts: an analysis of village survey data in India. J. Devel. Stud., $287-302$.

Bebchuk, L.A., Fried, J.M., 2003. Executive compensation as an agency problem. J. Econ. Perspect. 17, 71-92.

Bertrand, M., Mullainathan, S., 2001. Are CEOs rewarded for luck? The ones without principals are. Quart. J. Econ. 116 (3), 901-932

Bewley, T.F., 1999. Why Wages don't Fall During a Recession. Harvard University Press, Cambridge.

Bewley, T.F., 2002. Fairness, reciprocity, and wage rigidity. Cowles Foundation Discussion Paper No. 1383.

Bhattacharyya, S., Lafontaine, F., 1995. Double-sided moral hazard and the nature of share contracts. RAND J. Econ. 26 (4), 761-781.

Blanchflower, D.G., Oswald, A.J., 1988. Profit-related pay: prose discovered? Econ. J. 98, 720-730.

Blanchflower, D.G., Oswald, A.J., Sanfey, P., 1996. Wages, profits and rent-Sharing. Quart. J. Econ. 111, 227-252.

Bolton, G.E., Ockenfels, A., 2000. ERC - A theory of equity, reciprocity and competition. Amer. Econ. Rev. 90 (1), 166-193.

Casciaro, T., 2001. Interpersonal affect and the formation of joint production networks. Working Paper, Harvard Business School.

Charness, G., Dufwenberg, M., 2006. Promises \& partnership. Econometrica 74, 1579-1601.

Charness, G., Kuhn, P., 2007. Does pay inequality affect worker effort? Experimental evidence. J. Lab. Econ. 25, 693-723.

Charness, G., Rabin, M., 2002. Understanding social preferences with simple tests. Quart. J. Econ. 117 (3), 817-869.

Cox, J.C., Friedman, D., Gjerstad, S., 2007. A tractable model of reciprocity and fairness. Games Econ. Behav. 59 (1), 17-45.

Dufwenberg, M., Kirchsteiger, G., 2004. A theory of sequential reciprocity. Games Econ. Behav. 47, 268-298.

Dur, R., Glazer, A., 2008. Optimal incentive contracts when workers envy their bosses. J. Law, Econ., Organ. 24 (1), $120-137$.

Englmaier, F., 2005. A survey on moral hazard, contracts, and social preferences. In: Agarwal, B., Vercelli, A. (Eds.), Psychology, Rationality and Economic

Behaviour: Challenging Standard Assumptions. Palgrave/MacMillan, Hampshire/UK, pp. 125-139.

Englmaier, F., Leider, S., 2008. Contractual and organizational structure with reciprocal agents. CESifo Working Paper 2415.

Falk, A., Fischbacher, U., 2006. A theory of reciprocity. Games Econ. Behav. 54 (2), 293-315.

Fehr, E., Hart, O., Zehnder, C., 2008. Contracts as reference points - experimental evidence. NBER Working Paper 14501.

Fehr, E., Schmidt, K.M., 1999. A theory of fairness, competition and cooperation. Quart. J. Econ. 114 (3), 817-868.

Fehr, E., Schmidt, K.M., 2003. Theories of fairness and reciprocity - evidence and economic applications. In: Dewatripont, M., et al. (Eds.), Advances in Economics and Econometrics, Eighth World Congress of the Econometric Society. Cambridge University Press, Cambridge, pp. $208-257$.

Frank, R.H., 1984. Are workers paid their marginal products? Amer. Econ. Rev. 74 (4), 549-571.

Greenberg, J., 1993. The social side of fairness: interpersonal classes of organizational justice. In: Cropanzano, R. (Ed.), Justice in the Workplace. Erlbaum, Hillsdale, NJ.

Hart, O., Moore, J., 2008. Contracts as reference points. Quart. J. Econ. 123 (1), 1-48.

Hildreth, A., Oswald, A.]., 1997. Wages and rent-sharing: evidence from company and establishment panels. J. Lab. Econ. 15, 318-337.

Holmström, B., 1979. Moral hazard and observability. Bell J. Econ. 10 (1), 74-91.

Holmström, B., 1982. Moral hazard in teams. Bell J. Econ. 13 (2), 324-340.

Holmström, B., Milgrom, P., 1987. Agregation and linearity in the provision of intertemporal incentives. Econometrica 55, 303-328.

Itoh, H., 2004. Moral hazard and other-regarding preferences. Japanese Econ. Rev. 55 (1), 18-45.

Innes, R., 1990. Limited liability and incentive contracting with ex-ante action choices. J. Econ. Theory 52, 45-67.

Jewitt, l., 1988. Justifying the first-order approach to principal-agent problems. Econometrica 56 (5), 1177-1190.

Kandel, E., Lazear, E.P., 1992. Peer pressure and partnerships. J. Polit. Economy 100 (4), 801-817.

Kircher, P., Ludwig, S., Sandroni, A., 2009. Fairness: A critique to the utilitarian approach. Mimeo.

Knez, M., Simester, D., 2001. Firm-wide incentives and mutual monitoring at continental airlines. J. Lab. Econ. 19 (4), $743-772$.

Lazear, E.P., 1995. Personnel Economics. MIT Press, Cambridge.

Lord, R.G., Hohenfeld, J.A., 1979. Longitudinal field assessment of equity effects on the performance of major league baseball players. J. Appl. Psychol. 64 $19-26$.

Mas, A., 2006. Pay, reference points, and police performance. Quart. J. Econ. 121 (3), 783-821.

Milgrom, P., 1981. Good news and bad news: representation theorems and applications. Bell J. Econ. 12 (2), 380-439.

Milgrom, P., Roberts, J., 1992. Economics, Organization and Management. Prentice Hall, Englewood Cliffs, NJ.

Mirlees, J., 1999. The theory of moral hazard and unobservable behaviour, Part I. Rev. Econ. Stud. 66, 3-22.

Oliva, R., Gittell, J.H., 2002. Southwest Airlines in Baltimore. Harvard Business School Case 9-602-156.

O'Reilly, C., Pfeffer, J., 1995. Southwest Airlines: using human resources for competitive advantage (A). Stanford Graduate School of Business Case HR-1A.

Rabin, M., 1993. Incorporating fairness into game theory and economics. Amer. Econ. Rev. 83 (5), 1281-1302.

Rogerson, W., 1985. The first-order approach to principal-agent problems. Econometrica 53, 1357-1367.

Rotemberg, J., 1994. Human relations in the workplace. J. Polit. Economy 102 (4), 684-717.

Rotemberg, J., 2003. Altruism, reciprocity and cooperation in the workplace. In: Gerard-Varet, L., Kolm, S.C., Ythier, J.M. (Eds.), Handbook on the Economics

of Giving, Reciprocity and Altruism. North-Holland.

Thaler, R.H., 1989. Anomalies: interindustry wage differentials. J. Econ. Perspect. 3 (2), 181-193.

Young, H.P., Burke, M.A., 2001. Competition and custom in economic contracts: a case study of Illinois agriculture. Amer. Econ. Rev. 91, 559-573. 